\title{
Sex and coronary heart disease: the relative probability of dying in hospital
}

\author{
C J Currie, J R Peters
}

Department of Public Health Medicine, Bro Táf Health Authority, Temple of Peace and Health, Cardiff, Wales C J Currie

Department of Medicine, University Hospital of Wales, Cardiff, Wales

J R Peters

Correspondence to: Dr John Peters, Consultan Physician, University Hospital of Wales, Heath Park, Cardiff CF4 4XW, Wales.

e-mail: wmdcjc@cf.ac.uk
We have recently undertaken a study of diabetic patients that examines the influence of sex on the probability of presenting with coronary heart disease (CHD) related events. This work has been presented in a preliminary form, ${ }^{1}$ and contrasts with the findings of previous work. ${ }^{23}$

The relation between sex and heart disease is complicated by other factors-for example, in 1993 Petticrew et al showed that women were being discriminated against since they were less likely than men to undergo cardiac surgery. ${ }^{4}$ Women also appeared to receive treatment such as thrombolysis less frequently than men. ${ }^{56}$ In preparing our analysis of diabetic patients for full publication, it was pointed out by an informal but independent reviewer that one of the assumptions underlying the work, and critical to its validity, was mistaken. The assumption we had made was that women and men had equal probability of being admitted to hospital alive for treatment of cardiac events such as acute myocardial infarction, and therefore that both had equal probability of dying at home or outside hospital. Anecdotal reasons given for this possible source of bias include the hypothesis that general practitioners are less likely to identify chest pain in women as resulting from myocardial infarction (essentially discrimination), and that women themselves were less likely than men to identify cardiac symptoms.

\section{Patients and methods}

To test the hypothesis that women are more likely to die "at home" (meaning outside of hospital) from CHD related events, we obtained mortality data from the Office of Population Censuses and Surveys (OPCS) for the period 1993-95 for the South Glamorgan health authority (population 408 000). Details

Number of deaths inside and outside of hospital for heart disease by age and gender in South Glamorgan over three years (1993 to 1995 inclusive)

\begin{tabular}{|c|c|c|c|c|c|c|c|}
\hline & \multicolumn{6}{|l|}{ Age (years) } & \multirow[b]{2}{*}{ Total } \\
\hline & $<40$ & $40-49$ & $50-59$ & $60-69$ & $70-79$ & $80+$ & \\
\hline \multicolumn{8}{|l|}{ Male in hospital } \\
\hline Acute myocardial infarction & 2 & 20 & 55 & 109 & 184 & 108 & 478 \\
\hline Other forms of chronic ischaemic heart disease & 2 & 13 & 31 & 98 & 123 & 72 & 339 \\
\hline Heart failure & 8 & 5 & 23 & 47 & 121 & 102 & 306 \\
\hline Total & 12 & 38 & 109 & 254 & 428 & 282 & 1123 \\
\hline \multicolumn{8}{|l|}{ Male out of hospital } \\
\hline Acute myocardial infarction & 2 & 7 & 26 & 86 & 118 & 71 & 310 \\
\hline Other forms of chronic ischaemic heart disease & 1 & 9 & 24 & 87 & 108 & 82 & 311 \\
\hline Heart failure & 0 & 1 & 4 & 17 & 41 & 41 & 104 \\
\hline Total & 3 & 17 & 54 & 190 & 267 & 194 & 725 \\
\hline \multicolumn{8}{|l|}{ Female in hospital } \\
\hline Acute myocardial infarction & 2 & 2 & 10 & 49 & 112 & 161 & 336 \\
\hline Other forms of chronic ischaemic heart disease & 2 & 1 & 10 & 23 & 51 & 99 & 186 \\
\hline Heart failure & 6 & 4 & 14 & 43 & 92 & 211 & 370 \\
\hline Total & 10 & 7 & 34 & 115 & 255 & 471 & 892 \\
\hline \multicolumn{8}{|l|}{ Female out of hospital } \\
\hline Acute myocardial infarction & 0 & 3 & 12 & 23 & 71 & 138 & 247 \\
\hline Other forms of chronic ischaemic heart disease & 2 & 0 & 5 & 19 & 82 & 123 & 231 \\
\hline Heart failure & 1 & 1 & 0 & 9 & 27 & 108 & 146 \\
\hline Total & 3 & 4 & 17 & 51 & 180 & 369 & 624 \\
\hline Male population $(\times 1000)$ & $119 \cdot 2$ & $25 \cdot 0$ & $19 \cdot 4$ & $19 \cdot 1$ & $11 \cdot 7$ & $4 \cdot 1$ & $198 \cdot 5$ \\
\hline Rate/1000/year & 0.0 & 0.7 & $2 \cdot 8$ & $7 \cdot \overline{7}$ & $19 \cdot 8$ & $38 \cdot 7$ & $3 \cdot 1$ \\
\hline Female population $(\times 1000)$ & $116 \cdot 4$ & 24.9 & 19.9 & $21 \cdot 2$ & $17 \cdot 0$ & $10 \cdot 5$ & 209.9 \\
\hline Rate/1000/year & 0.0 & 0.1 & 0.9 & $2 \cdot \overline{6}$ & $8 \cdot 5$ & $26 \cdot 7$ & $2 \cdot 4$ \\
\hline \multicolumn{8}{|l|}{$\begin{array}{l}\text { Odds ratio of out of hospital to in hospital death } \\
\text { in males } v \text { females }\end{array}$} \\
\hline Acute myocardial infarction & 0.0 & $4 \cdot 3$ & 2.5 & 0.6 & 1.0 & $1 \cdot 3$ & $1 \cdot 1$ \\
\hline $95 \%$ confidence interval & $0 \cdot 0-14 \cdot 8$ & $0.44-48.64$ & $0 \cdot 88-7 \cdot 39$ & $0.32-1.09$ & $0.67-1.47$ & $0.88-7.93$ & $0.71-1.42$ \\
\hline Other forms of chronic ischaemic heart disease & 2.0 & 0.0 & 0.6 & 0.9 & $1 \cdot 8$ & $1 \cdot 1$ & 1.4 \\
\hline $95 \%$ confidence interval & & $0-29 \cdot 68$ & $0 \cdot 16-2 \cdot 44$ & $0.45-1.92$ & $1 \cdot 16-2 \cdot 9$ & $0.71-1.68$ & $1.05-1.75$ \\
\hline Heart failure & & $1 \cdot 3$ & 0.0 & 0.6 & 0.9 & $1 \cdot 3$ & $1 \cdot 2$ \\
\hline $95 \%$ confidence interval & $t$ & $\star$ & $0-3.01$ & $0 \cdot 21-1 \cdot 56$ & $0 \cdot 48-1.57$ & $0 \cdot 81-1 \cdot 23$ & $0.86-1.57$ \\
\hline Total & $1 \cdot 2$ & $1 \cdot 3$ & $1 \cdot 0$ & $0 \cdot 6$ & $1 \cdot 1$ & $1 \cdot 1$ & $1 \cdot 1$ \\
\hline $95 \%$ confidence interval & $0.14-10.09$ & $0 \cdot 27-5 \cdot 84$ & $0 \cdot 04-2 \cdot 07$ & $0.4-0.88$ & $0.88-1.46$ & $0.9-1.44$ & $0.94-1 \cdot 25$ \\
\hline
\end{tabular}

Source, Office of Population Censuses and Surveys. 
of the cause of death (ICD9), sex, age, and the location of death were identified. These data were analysed to determine the relative likelihood (the odds ratio) of men and women dying at home or in hospital from acute myocardial infarction (ICD9 410), other forms of chronic ischaemic heart disease (ICD9 414), and heart failure (ICD9 428). The odds ratio is the ratio of the frequency of death at home in the male population to the total number of related male deaths minus this value, divided by the same calculation for the female population. If there is no difference in the experiences of the two groups, the resulting value will be 1 .

\section{Results}

There were 15345 deaths over the study period. Of these, $3364(22 \%)$ had a primary cause of death in one of the three diagnostic categories, giving an average annual crude mortality rate of 2.7 per 1000 population per year. Men had consistently higher age specific mortality rates from CHD-for example, in the 80 years and older age group the mortality rates were 39 and 27 per 1000 population per year for males and females, respectively. After aggregation of the above diagnoses and age specific subgroups, there was a slight increase in the probability of men dying in hospital but this was not significant (odds ratio $=1 \cdot 1$, $95 \%$ confidence interval $=0.94$ to $1 \cdot 25$ ). The disease and age and sex specific values are shown in the table. Given the 49 significance tests in the table, two tests would be expected to be "significant" at the $5 \%$ level as a random finding.

\section{Discussion}

Although men and women differ in the probability of developing heart disease, they have virtually the same probability of dying at home (or outside hospital) from CHD - that is, they have the same probability of being hospitalised after a CHD event. If there is any discrimination within the system, it takes place after admission to hospital and is less likely to be an issue of variable referral practice from the community to hospital.

1 Hanna FWF, Currie CJ, Rees A, Peters JR. Gender difference in the relative risk of ischaemic heart disease in diabetes. Diabetologia 1996;39(Suppl 1):A194.

2 Barrett-Connor EL, Cohn BA, Wingard DL, Edelstein SL. Why is diabetes mellitus a stronger risk factor for fatal ischaemic heart disease in women than in men? The Rancho Bernardo Study. $\mathscr{f} A M A$ 1991;265:627-31.

3 Kannel WB. Lipids, diabetes and coronary heart disease: insights from the Framingham Study. Am Heart $\mathcal{f} 1985$; 110:1100-7.

4 Petticrew M, McKee M, Jones J. Coronary artery surgery: are women discriminated against? $B M F$ 1993;306: $1164-6$

5 Jha $P$, Deboer D, Sykora K, Naylor CD. Characteristics and mortality outcomes of thrombolysis trial participants and non-participants: a population based comparison. $\mathcal{F}$ Am Coll Cardiol 1996;27:1343-8.

6 Lincoff AM, Califf RM, Ellis SG, Sigmon KN, Lee KL, Leimberger JD, et al. Thrombolytic therapy for women with myocardial infarction: is there a gender gap? Thrombolysis and angioplasty in myocardial infarction study groups. $7 \mathrm{Am}$ Coll Cardiol 1993;22:1780-7. 